\title{
Constitución de la lengua española o castellana*
}

MIGUEL ÁNGEL ÁVILA BAYONA**

Docente (r) Universidad Pedagógica y Tecnológica de Colombia, Colombia miguel18angel@gmail.com

Recepción: 29 de julio de 2016

Aprobación: 03 de octubre de 2016

Forma de citar este artículo: Ávila Bayona, M.Á. (2017). Constitución de la lengua española o castellana. Cuadernos de Lingüística Hispánica, (29), 203-221. doi: http://dx.doi.org/10.19053/0121053X.n29.2017.5866

* Artículo de reflexión.

** Docente (r) Universidad Pedagógica y Tecnológica de Colombia. Código ORCID: orcid.org/0000-0002-2073-818X 


\section{Resumen}

Tras la conquista y colonización españolas, los pueblos subdesarrollados de América debieron asumir la lengua de sus conquistadores. Era la lengua que el reino de Castilla ya había impuesto a otras provincias ibéricas (nombre griego), con excepción de la portuguesa. Esta lengua recién estaba alcanzando rigurosidad gramatical, como consecuencia de la evolución del latín impuesto por los romanos desde el año 19 antes de Cristo en la Península Hispánica. Década tras década el latín se alteró en su fonética, morfología, sintaxis y semántica hasta obtener diversos dialectos; algunos, como el castellano, se distanciaron de su lengua madre y se hicieron lenguas con sus propias gramáticas. Las posteriores invasiones, visigodas y árabes, apenas dejaron huella en el castellano, porque los hispanos (nombre romano que significa tierra de conejos) poseían una cultura más sólida que la de sus invasores. El español que hoy se habla procede del latín hablado tanto por la gente culta y por el vulgo o pueblo de entonces, como del 'bajo latín' hablado y escrito en la Edad Media (siglos V-XVI). Cada uno en su espacio y momento fue responsable de cambios fonéticos, morfológicos, sintácticos y semánticos. Hoy la evolución prosigue, pese a la universalidad y el enriquecimiento de los medios de comunicación lingüísticamente unificadores.

Palabras clave: lenguaje, latín, evolución, español, invasión, comunicación, forma, contenido.

\section{The Constitution of the Spanish or Castilian Language}

\section{Abstract}

After the Spanish conquest and colonization, the underdeveloped nations of America had to accept the Spanish language as their own. The language that the kingdom of Castille had already been imposed on other Iberian provinces, with the exception of Portugal. At this moment, this language was just acquiring grammatical accuracy, as a consequence of the evolution of the Latin language, introduced in the Hispanic peninsula during the Roman empire in the year 19 B.C. Over the decades, Latin phonetics, morphology, syntax and semantics were altered to form many dialects. Some of them, like the Castilian, took a distance from their mother tongue and became different languages altogether, with their own grammatical systems. Later Visigoth and Arab invasions left a scarce trace on the Castilian language, because Hispanics (Roman name meaning land of rabbits) had 
a more solid culture than their invaders. The Spanish we speak today comes from the Classical Latin as well as from the Vulgar Latin, Late Latin and Medieval Latin, spoken and written in the Middle Ages (V-XVI centuries). Each of these periods were important to the phonological, morphological, syntactic and semantic changes that occurred in Spanish. Nowadays, Spanish keeps evolving, despite universality and the expansion of our linguistically unifying communication media.

Key words: Language, Latin, Evolution, Spanish, Invasion, Communication, Shape, Content.

\section{Constitution de la langue espagnole ou castillane}

\section{Résumé}

Après la conquête et colonisation espagnoles, les peuples sous-développés du continent américain ont dû assumer la langue des conquérants. C'était la langue que le royaume de Castille avait déjà imposé à d'autres provinces ibériques (nom grec) à l'exception de la portugaise. Cette langue était à peine en train d'atteindre sa rigueur grammaticale, comme conséquence de l'évolution du latin imposé par les romains dès l'an 19 avant Jésus-Christ dans la Péninsule Hispanique. Décennie après décennie, le latin a subi des altérations par rapport à sa phonétique, morphologie, syntaxe et sémantique pour obtenir divers dialectes ; quelques-uns comme le castillan, ont pris de distance avec sa langue mère et sont devenus des langues ayant leurs propres grammaires. Les invasions qui se sont succédées, wisigothes et arabes, ont à peine laissé un emprunt sur le castillan, parce que les hispaniques (nom romain qui signifie terre de lapins) avaient une culture plus solide que celle des envahisseurs. L'espagnol parlé aujourd'hui vient du latin parlé par les gens cultivés et le peuple de cette époque-là, come du "bas latin", parlé et écrit au Moyen Âge (Ve-XVIe siècles). Chacun dans son espace et moment a été responsable de changements phonétiques, morphologiques, syntaxiques et sémantiques. Aujourd'hui l'évolution continue, malgré l'universalité et l'enrichissement des moyens de communication linguistiquement unificateurs.

Mots clés: Langage, latin, évolution, espagnol, invasion, communication, forme, contenu. 


\section{Constituição da língua espanhola ou castelhana}

\section{Resumo}

Após a conquista e a colonização espanholas, os povos subdesenvolvidos da América deviam assumir a língua de seus conquistadores. Era a língua que o reino de Castela já havia imposto a outras províncias ibéricas (nome grego), com exceção da portuguesa. Esta língua recém estava alcançando rigorosidade gramatical, como consequência da evolução do latim imposto pelos romanos desde o ano 19 antes de Cristo na Península Hispânica. Década trás década o latim alterou-se em sua fonética, morfologia, sintaxe e semântica até obter diversos dialetos; alguns, como o castelhano, distanciaram-se de sua língua materna e tornaram-se línguas com suas próprias gramáticas. As posteriores invasões, visigodas e árabes, apenas deixaram as suas marcas no castelhano, porque os hispanos (nome romano que significa terra de coelhos) possuíam uma cultura mais sólida que a de seus invasores. O espanhol usado hoje procede do latim falado tanto por gente culta e pelo vulgo ou povo da época, como do 'baixo latim' falado e escrito na Idade Media (séculos V-XVI). Cada um em seu espaço e momento foi responsável pelas mudanças fonéticas, morfológicas, sintáticas e semânticas. Hoje a evolução prossegue, apesar da universalidade e do enriquecimento dos meios de comunicação linguisticamente unificadores.

Palavras chave: Linguagem, latim, evolução, espanhol, invasão, comunicação, forma, conteúdo. 


\section{Introducción}

El presente artículo es un apartado de una reflexión analíica más extensa, apoyada, para este caso, en investigaciones ya concluidas por los Historiadores de la lengua española, llamados también Gramáticos historicistas. Aquí se asume, someramente, las incidencias lingüística, social, política y militar que dieron origen a la lengua española. El español que hoy hablamos es el resultado de múltiples interacciones, consecuencia de tales influencias. Por tanto, nuestro objeto de reflexión es entender que si bien el español tiene un tronco único, el latín, algunas de sus raíces pertenecen a otros árboles. Esto significa que la gramática española es fundamentalmente latina, con matices del griego (que, por ejemplo, emplea los artículos masculino, femenino y neutro, mientras que el latín no), de las lenguas ibéricas, llamadas prerromanas, y de culturas invasoras o que mantuvieron intercambio comercial con Hispania. Es una de las razones de por qué esta lengua tiene diferencias progresivamente marcadas con las lenguas italiana, francesa y rumana, y menores con el portugués, gestado en la misma Península Ibérica.

Desde 1492, cuando Antonio de Nebrija publicó la Gramática de la lengua castellana, se ha hecho énfasis en la conservación de las formas fonéticas, sintácticas, morfológicas y semánticas de esta lengua y desde entonces nos acostumbraron a creer que el español era un hijo del latín, lo cual es cierto solo parcialmente. Entendamos, entonces, que el anhelo de mantener pura la lengua no es porque ad aeterno los cuatro niveles del lenguaje se mantengan inalterados, sino porque se necesitan para que la interacción entre los hablantes esté exenta de ambigüedades y conlleve una comunicación eficaz y eficiente.

El propósito comunicativo es el de aportarle al estudiante de lingüística y de otras áreas humanas, que en sus estudios universitarios careció de tal información (fundamental en el análisis lingüístico de orden formal o conceptual ya en la oralidad ya en la lectoescritura literaria y científica), unas informaciones que por razones de tiempo y de otros intereses académicos han quedado relegadas, pero que son pertinentes para sus investigaciones acerca del discurso, del texto o del lenguaje en general, así como para entender la gramática y los usos de la palabra. Para alcanzar este propósito, se recurre a las fuentes más autorizadas en el análisis de lo que causó que el latín en España se transformara en una lengua distinta de sus hermanas y abandonara, parcialmente, las formas y la gramática latinas. De momento se hablará del surgimiento, formación y desarrollo del español; luego, como sustento de 
lo afirmado, se expondrá la historia de algunos lexemas y su incidencia en la morfología, sintaxis y semántica de las palabras y la gramaticalidad de las oraciones.

Surtidas las bases para la comprensión y mejor uso morfofonémico y sintáctico semántico del español, en próximos trabajos se abordará someramente la estructura textual y discursiva, fundamentales para una comunicación cada vez más eficaz y eficiente.

Una lengua es ella misma lenguaje, esto es, se hace superestrato de otra(s) cuando es más rica lingüísticamente y más apropiada a las necesidades, progreso y desarrollo cultural y comercial de los usuarios. Da prestigio a quien la habla, como ocurrió en los siglos antes de Cristo, que los griegos, en su esplendor, gozaban de un espacio sociocognitivo, de orden filosófico y artístico (escultura y literatura), superior al de sus invasores, los romanos, por lo que estos fueron lingüística y culturalmente rechazados y obligados a ser saqueadores de cultura. Un tanto ocurrió en España ya con las invasiones germánicas por parte de los visigodos, ya con la invasión mora 0 árabe que permaneció en algunas provincias por cerca de ochocientos años, mas apenas si dejaron huella lingüística.

La invasión española en América, que llegó repartiendo destrucción y muerte, logró imponerse en comunidades que carecían de desarrollo industrial y militar, y cuya cultura estaba en estrecha relación con el mundo inmediato que vivían. Por sometimiento y por supervivencia, los nativos se vieron impelidos a aprender la lengua de sus invasores. Desde entonces es nuestra lengua materna y de ella vivimos orgullosos; la estudiamos por su forma, su contenido y sus usos.

Históricamente, en tales estudios se destacan dos grandes estadios. Uno y el primero, importante en su momento, fue el estudio de las formas de esta lengua con el fin de saber cómo estaba hecha, para poder usarla correctamente y, de ser posible, con "esplendor" como reza el lema de la Real Academia de la Lengua en su "Fundación, y Estatútos de la Real Académia Españóla" (sic.). 1715, impreso en la portada de la primera edición: "Limpia, fija, da esplendor". Rae).

El segundo momento de estudio que se reflexionará analíticamente en capítulos posteriores, no desconoce los saberes del primero; lo considera indispensable para saborear el sentido (lo individual en el momento de la comunicación) y el significado (lo social, abstracto y relativamente permanente) de lo que está impregnada toda forma de lenguaje (verbal y no verbal) y toda expresión lingüística (la palabra entendida como un complejo coherente de signos verbales empleados por un hablante - oyente real en situaciones reales de comunicación oral o escrita). 


\section{Formación y primeros estadios de la lengua española o castellana}

\section{Por qué castellano y por qué español}

Los latinoamericanos nos referimos a nuestra lengua materna como española, porque fueron los españoles, quienes en su conquista y colonia, nos impusieron militar y políticamente su lengua, además de sus costumbres y tradiciones sociales y culturales, su religión, sus formas de gobierno. Son los mismos españoles los que llaman castellana a su lengua nacional, porque saben que el reino de Castilla se impuso sobre las demás provincias como las de León, Aragón, Navarra, Andalucía, Murcia y Extremadura porque las leyes, la religión y la literatura castellanas gozaban de prestigio. Históricamente, los españoles, sin embargo, se han resistido a aceptar el superestrato castellano, lo que ha permitido la existencia de lenguas regionales como la catalana, la valenciana, la mallorquín, entre otras. En Latinoamérica, Ecuador y Perú aceptaron el español sin renunciar a la lengua aborigen, la quechua. En Colombia, los distintos gobiernos de turno relegaron las numerosas lenguas indígenas a las comunidades que las hablaban, y le dieron preeminencia al español como lengua oficial ${ }^{3}$ única.

El español actual es una mezcla de varios idiomas, cuya proporción de aporte corresponde, en alto porcentaje al latín, en menor grado al griego y al árabe, y en un porcentaje mínimo a otros idiomas. Con el avance creciente ya no de la literatura y la filosofía, sino de la industria, de la tecnología, de la globalización comercial y cultural, el idioma inglés ha penetrado en el español con léxico nuevo, pero muy poco prevalecerá porque los elementos industriales y tecnológicos cambian, desaparecen para que lleguen otros. Esta invasión lingüístico-cultural afecta principalmente a la semántica y semiótica del lenguaje. Las formas extranjeras las adecuamos a nuestra fonética y morfología: 'chou' 'tuitiar', 'uasapiar' 'casé', 'vidiobín', la madán y el mecié', 'lo estamos testiando', 'la lideresa'.

Los ibéricos, cartagineses (invasores venidos del norte de África) y celtas ${ }^{4}$, primitivos habitantes de la península ibérica, dejaron huella léxica (y seguramente fonética que no es posible confrontar) en palabras como vega (de 'vai'= 'río' y ' $k a$ '= 'región'), izquierdo, abedul, alondra, brío, caballo, cabaña, camino, camisa cerveza, legua, pieza,

3 "PREÁMBUlo. EL PUEBLO DE COLOMBIA Constitución Política de Colombia Artículo 10.- El castellano es el idioma oficial de Colombia. Las lenguas y dialectos de los grupos étnicos son también oficiales en sus territorios. La enseñanza que se imparta en las comunidades con tradiciones lingüísticas propias será bilingüe”.

4 Los celtas corresponden en la historia antigua a un conjunto de pueblos europeos que hablaban lenguas afines; lo que demuestra que hubo una lengua madre, que en el desplazamiento de las comunidades por el territorio europeo, se transformó primero en variantes dialectales y luego en lenguas diferentes. 
salmón; los sufijos en 'rro' como pizarra, guijarro, cerro, carro, perro, etc. ${ }^{5}$ Fueron permeados, aproximadamente desde el año 19 a.C., por hablantes del latín venidos de Roma, que encarnaban un alto poder de orden militar, comercial, económico y cultural. "La romanización de la Península fue lenta [...], pero intensa, que hizo desaparecer las lenguas anteriores a excepción de la zona vasca. No sobrevivieron más que algunas palabras especialmente significativas y muy arraigadas y unos cuantos sufijos" (Lapesa, 1981, pp. 36-37).

La mezcla de las lenguas ibéricas (gálica, asturiana, cantábrica, vasca, celta, lusitana, cretana, etc.) con el latín, más el analfabetismo de los invadidos, originó el llamado latín vulgar que poco a poco se hizo a su propia gramática, cada vez más alejada de la gramática latina, hasta convertirse en varias lenguas nuevas (castellano, gallego, provenzal, vasco, catalán, navarro-aragonés).

El latín que los conquistadores romanos llevaron a la Península Ibérica no era un idioma puro (ni jamás lo ha sido lengua alguna); estaba impregnado tanto de sabiduría griega como de aportes de lenguas con las que los romanos habían tenido contacto antes de la invasión ${ }^{6}$. El aporte griego en la Península ocurrió desde antes de la invasión romana, mediante el comercio y la agricultura, pero luego los intelectuales latinos optaron por la lengua griega para propósitos filosóficos e investigativos. Así, a quien atendía empíricamente la dentadura se le decía dentista del latín 'dens, dentis' (diente), mas a quien lo hacía bajo conocimientos científicos se le llamó odontólogo del griego 'odús, odóntos'. Caso similar se dio con oculista vs optómetra y oftalmólogo. Las locuciones griegas que entraron al español pasaron primero por el latín que les asignaba la pronunciación latina. Así, mientras en griego se decía Jristús, jáos, en español se dijo respectivamente 'Cristo', 'caos'.

Actualmente un $20 \%$ del vocabulario español es de origen griego, en especial en las actividades académicas orales y escritas; sin embargo, en el siglo XXI los investigadores y tecnólogos prefieren el idioma inglés. Las ciencias, las artes y algunos oficios recurrieron a locuciones griegas, por lo que en páginas posteriores haremos un punto y aparte para refrendar este aporte, útil a los académicos y demás profesionales, luego de entender las

5 El vocabulario que se menciona en este escrito ha sido tomado, en buena parte, de Menéndez Pidal (1966). Manual de gramática bistórica española (12 ed). Madrid: Espasa-Calpe. También de Alatorre, A. (1979). Los 1001 años de la lengua española. México D. F.: Fondo de Cultura Económica.

6 "Como parece probable que muchos de los soldados y colonos romanos llegados a España procedieran de zonas donde existía una situación de bilingüismo entre la lengua de Roma y osco o umbro, se ha querido demostrar que el latín de estos hablantes estaba impregnado de rasgos producto del contacto de lenguas". (Penny, 1991, p. 27). 
implicaciones semántico-comunicativas de la transformación de la lengua latina en una lengua como la española.

Pese a sufrir invasiones tanto germánicas, a través de los visigodos entre los años 414 a 711, como árabes desde el año 711 hasta el año 1492, el latín no dejó de ser la lengua oficial de España, pero en el uso popular desde el comienzo se impregnó de las estructuras de las lenguas aborígenes e invasoras. La transformación se dio, por una parte en estas diversas invasiones militares, por otra, en el uso oral generalmente descuidado tanto en fonética, morfología o sintaxis, como en el valor semántico que los lexemas iban adquiriendo por las necesidades que demandaba la comunicación diaria.

El período visigótico contribuyó a la formación del latín vulgar romanceado por el contacto con esta cultura germánica que deja herencia lingüística en algunos nombres propios como: Gonzalo, Ramiro, Alfonso, Froilán, Federico, Ricardo, Enrique, Clodoveo, Luis, Rosendo, Elvira, Bermúdez, al igual que verbos y nombres como: guardar, albergar, agasajar, ataviar, robar, ganar, guiar, guarecer, guarnecer, guerra, facha, arenga, lbergue, espuela, fieltro, bando, aleve, ropa, espora, beraldo, escarnio, ardido, falda, burgués, tregua, guardia, espía, yelmo, guante, cofia, dardo, brida, estribo, espuela, etc.

El predominio árabe lo fue un poco en las artes y muy poco en la literatura; no fue superior a la cultura ibérica ${ }^{7}$, lo que impidió que el árabe y el mozárabe se impusieran como lenguas nacionales; no obstante dejaron huellas morfológicas, fonéticas y léxicas; por ejemplo, incidieron en el cambio fonético de la $/ s$ / de algunas palabras por $/ j /$ como en succus por jugo, sapone por jabón, jeringa, jilguero, Juárez (Suárez). En morfología es notable el sufijo /-i/ para adjetivos como: carmesí, turquí, marroquí, tunecí, baladí, y el sustantivo jabalí. (El sustantivo tití, según la zoología corresponde al sonido que emite el animal que lleva este nombre. El sustantivo aji viene de 'haxi', palabra taína, lengua de las islas del Caribe). El prefijo /al- (a)-/ como en: almacén, Alcántara, alcalde, aceite, azogue (mercado, mercurio), azúcar, alcázar, almendra, almeja, aljibe, algarabía, albaricoque, acelga [...] Al léxico se incorporaron palabras ya de tipo militar como: atalaya, adalid (caudillo, jefe, guía), ronda, arrebatar, alguacil, albacea, ya de carácter comercial como: almacén, almoneda (subasta), quilate, arroba, quintal, fanegada, etc., de oficios varios como: alfarero, albañil, de lugares como: zaguán, azotea, alcantarilla, alfeizar (puerta), alcoba, acequia, alberca.

7 Roma tampoco logró imponer el latín en Grecia, lo que prueba que la cultura y la literatura siempre han estado y seguirán estando por encima de cualquier otro poder cuando se trata de la estructura lingüística. 
Luego de prolongadas luchas, poco a poco los moros fueron sometidos, y se cambiaron las costumbres orientales por las occidentales, se recuperó la tradición lingüística con un latín evolucionado, para entonces, en varios dialectos cercanos a lo que hoy es nuestro español y se dio comienzo a la producción literaria en la nueva lengua. Tras acabar con las invasiones, España entró enseguida en luchas internas en pro de un país unificado, a las órdenes de un único monarca; y el reino de Castilla, entre los años 1067 y 1140 se impuso política, militar y lingüísticamente. Para entonces, España entra en un período intelectual que se narra en el "Cantar de Mío Cid Campeador". Entre los años 1609 y 1613, el rey Felipe III terminó de expulsar a los moros que persistían en la lucha militar. Por orden del rey Alfonso X, en España se proclamó en el año 1200 el dialecto castellano como la lengua nacional.

\section{Transformación del latín en castellano y español}

La inevitable evolución de cualquier lengua viva nos permite reconocer, que en español nacieron, paralelamente, una lengua vulgar y una culta que se influían mutuamente. El latín culto se enseñaba y con él se escribía, mientras que el vulgar era "empleado en las conversaciones de las gentes medias y las masas populares... apegadas a usos antiguos" (Lapesa, 1981, pp. 68-69). La vulgar la usa el vulgo o pueblo, en su mayoría analfabeto, que indefectiblemente solo se atiene al oído; la culta la usan los letrados, especialmente en la escritura y en las formalidades políticas, académicas y sociales, "cuando esta lengua ya era muerta" (Menéndez, 1966, p. 9). Además de las formas cultas y vulgares, Camacho et al. (1998) diferencia el "tecnicismo que es todo vocablo propio de una ciencia, que ha sido formado, generalmente, a partir de elementos griegos" (p. 45). Y continúa en punto y aparte: "Los términos que utilizan la ciencia, las artes, y la técnica en general, no están hechos al azar; su creación obedece a razones de orden, claridad, precisión, coherencia y universalidad".

Con frecuencia, los letrados de la Edad Media intentaron retomar el cultismo latino, pero estaban impelidos a usar la morfología de la nueva lengua, por lo que contamos con algunas voces semicultas. Verbi gratia, en latín se decía titulum (palabra proparoxítona o esdrújula. En latín no se usaban los acentos ortográficos), pero por influencia del latín vulgar no pronunciaban el sonido $/ \mathrm{m} /$ y después optaron por la pronunciación abierta ${ }^{9}$, es decir, el sonido $/ u /$ lo cambiaron por $/ 0 /$, mientras en el lenguaje coloquial evolucionaba a tídulo ---> tidlo --->tilde. Esta palabra evolucionó tardíamente, pues la /i/ breve

8 El nombre Cid procede del árabe que significa señor; y se le califica de campeador porque Rodrigo Díaz (1048-1099) nacido en Vivar, provincia de Castilla, luchaba en el campo de batalla a nombre de quien mejor le pagara.

9 Son abiertas, fonéticamente, la vocal /a/ la más abierta, $/ e / \mathrm{y} / 0 /$ abiertas medias, $\mathrm{y} / u-i /$ cerradas. 
acentuada en otros casos siempre daba /e/; de ser así tendríamos tedlo---> teldo --->tejo. Algo similar ocurrió con capitulum que generó capítulo y cabildo respectivamente y no cabeldo ni cabejo.

En síntesis, las voces semicultas del español: $1^{\circ}$. unas pasaron de manera temprana del latín culto al hablado, por lo que su evolución quedó a mitad de camino; $2^{\circ}$. otras se tomaron en la Edad Media del latín escrito; $3^{\circ}$. otras se recuperaron tardíamente de textos antiguos $y, 4^{\circ}$. otras porque eran usadas frecuentemente por los líderes sociales como el clero.

En el habla popular no era común la combinación 'vocal - consonante velar consonante', por lo que se decía: dino, malino, coluna, efeto, mientras que en el habla culta se decía: digno, maligno, columna, efecto ${ }^{10}$. Aunque en el español actual predomina el uso culto de estas expresiones, no es raro escuchar la forma vulgar en personas de escasa o nula formación escolar.

El cultismo no consiste en mantener exacta la palabra latina, sino fundamentalmente la raíz y el significado latinos como en:

Continuitatem ---> continuidad; amabilitatem ---> amabilidad; capitulum ---> capitulo laborare ---> laborar.

Del léxico de la lengua latina se derivan otros lexemas y otros significados, porque surgen nuevas necesidades comunicativas. En ocasiones el significante amplía el valor referencial como en: serra que hacía referencia al "instrumento de carpintería, se amplió a cadena de montañas" (Menéndez, 1966, p. 5). Cubiculo, habitación, se refiere también a oficina pequeña. Catedra, asiento, por metonimia es asignatura impartida en el aula escolar. En la mayoría (¿o totalidad?) de los casos, las palabras latinas dieron origen a lexemas cultos con morfofonología española, así como a lexemas coloquiales como en:

Apes, apis (abeja) ---> apicula (abeja pequeña) derivó en cultismos del español como 'apicultor', 'apicultura', 'apícola'. La transformación fonética del lexema 'apicula' en el vulgo llevó, tras varios años, a generar la palabra 'abeja' y sus respectivos derivados como 'abejorro', 'abejón' 'abejita'. Pero ¿cómo fue tal evolución? Una vez más, por la pereza articulatoria y el descuido en la pronunciación ${ }^{11}$, siempre comunes en todo idioma; por

10 El uso es oral no escrito. En el español coloquial se oye decir: "el Vítor", "el Hétor", "la letura del libro".

11 La pereza y el descuido lingüísticos han originado palabras nuevas en la oralidad, o en la escritura e incluso en ambas. Así, por ejemplo, 'el latril' fue desplazado por 'el atril'. Se escribe 'línea' y se pronuncia 'linia'. Las gentes preguntaban al comienzo de una interacción social: “¿qué hubo?”, pero como tendemos a cambiar la /e/ por /i/ se impuso la nueva fórmula de saludo, exclamativa, iquihubo! distinta de la interrogativa. 
ejemplo, en el español actual, coloquialmente se dice "taluego" en vez de "hasta luego"; "¿p'ónde va?", etc. En latín 'apicula' tiene acento fuerte en la /-i-/ y débil en /-u-/ lo que obliga a la desaparición de la segunda vocal. Además, la consonante /-p-/ fonéticamente es sorda (porque las cuerdas vocales no vibran) y por estar entre vocales (que siempre son sonoras), se sonoriza y se reemplaza por /-b-/. Años después, la combinación /-kl-/ (sorda sonora) es reemplazada por $/-j-/$.

Del genitivo plural Lacteum de lac, lactis tenemos en español el lexema vulgar 'leche' y los lexemas cultos 'lactosa', 'lácteo', 'láctico'. Debemos aclarar que los hablantes escogían una forma de la declinación de la palabra, como en este ejemplo el caso genitivo plural, en otros el acusativo singular, en otros el nominativo singular, según los usos más frecuentes en la comunicación oral. En este y otros ejemplos, entendemos que los sonidos /-kt-/ se alteraron en la pronunciación, porque la consonante glotal o velar /-k-/ es atraída por la consonante postdental /-t-/ y constituyen la consonante africada que corresponde a un sonido consonántico compuesto, caracterizado porque la boca se cierra dejando un pequeño resquicio para obstruir la salida de aire, seguida, en fracciones de segundo, por una fricción o salida del mismo a través de los laterales de la boca y por entre los dientes, mientras la parte media de la lengua se apoya en los alvéolos, formando el sonido /-ch-/ que fonéticamente se representa /-t $t$ - L Los sonidos $/-u-/$ y $/-m /$ desaparecen porque aquella vocal es tónicamente más débil que /-e-/. Por ser /-a-/ una vocal abierta e /-i-/una vocal cerrada anterior, las dos se atraen y se encuentran en la vocal media anterior $/-e-/ .{ }^{12}$ De ahí tenemos Lacteum --->lacteu --->laiteo --->laicheo --->leche.

El lexema 'cabeza' procede del latino caput (nominativo singular), capitis (genitivo singular). Los hablantes optaron por el nominativo plural capita (las cabezas). Primero el sonido /-p-/ sordo intervocálico se sonorizó en /-b-/, la primera /-i-/ inacentuada no desapareció sino que se convirtió en /-e-/; la consonante /-t-/ sorda intervocálica interdental y no dental se mantuvo interdental sorda, por lo cual se escribe con $Z$ que fonéticamente se representa con $/-\theta-/$. Cabe anotar que no todos los sentidos que hoy tenemos de 'cabeza', como "estar a la cabeza", "le dio por la cabeza" existían en latín. Expresiones como 'cefalea', 'encefalitis', 'acéfalo', 'bicéfalo', etc., proceden del griego y son palabras especializadas,

12 En la transformación del latín clásico al español, las vocales y consonantes se vieron afectadas en la oralidad, no en la escritura, por varias razones: el analfabetismo, que llevaba a los hablantes a repetir lo que oían como creían haber oído (afectados por ruidos, por desatención, por pronunciación deficiente, por no ver la palabra escrita o no saberla leer); la ausencia de medios de comunicación que obligaba a los individuos y a las comunidades a estar alejados y, en consecuencia, a darle nuevos matices fonéticos y semánticos a las expresiones; las vivencias dadas por el clima, la orografía; las condiciones políticas, sociales y culturales, etc. Cuando el español dejó de ser dialecto y se convirtió en lengua, las formas vulgares entraron a ser parte de la gramática de la lengua y a hacer parte de la estructura de la lengua al lado de los cultismos que no logramos diferenciar cuando desconocemos su etimología. 
académicas, tecnicismos en términos de Camacho y otros (1998, p. 45), y su uso es menos frecuente en el lenguaje coloquial. De la palabra culta latina tenemos en español: 'capital', 'capítulo', 'capitalismo', 'descapitalizado', 'decapitar', 'acápite'. De la vulgar encontramos cabezal, cabezote, descabezar, encabezar, cabecilla.

El lexema auris, auris, 'la oreja' también tenía su correspondiente diminutivo auricula que le dio vida al término vulgar 'oreja' que en español no se entiende como diminutivo. Su evolución se explica porque la vocal / $a$ / abierta central se atrae con la vocal $/ u$ / velar cerrada y se encuentran en la vocal media posterior /o/. La vocal / $i$ /generalmente se convierte en /e/y, como ya sabemos, la forma diminutiva/-cula/ se transformó en /-cla/y esta en /-j-/ como se señaló arriba. La misma palabra culta se usa en el español actual, pero con tilde. También tenemos 'auricular', 'auriforme'. La forma vulgar tiene como derivados 'orejón', 'desorejar', 'orejita' (diminutivo de diminutivo).

El lexema latino laborare que tiene como sílaba acentuada la penúltima, solo eliminó la vocal átona /-e/; por lo que tenemos los cultismos 'laborar', 'elaborar', 'reelaborar', 'laborable', 'laboratorio', 'laborioso', 'labor' (apócope). Como lexemas vulgares más comunes están, 'labrar' (síncopa), 'labrador', 'labranza', 'labrantío', 'labriego'.

La evolución y transformación del latín a las demás lenguas romances fueron léxicas, morfológicas y fonéticas. Las semánticas ${ }^{13}$ no las da la misma lengua, el latín, sino las vivencias de sus usuarios, de la misma manera como ocurre actualmente en cualquier lengua. Porque las palabras y las proposiciones no son lo que significan sino lo que pueden significar. El significado no está en la palabra sino en su uso interactivo. Cada lexema tiene una base sémica y de ella surgen por asociación conceptual, experiencial, cognitiva 0 gramatical sustantivos, adjetivos, verbos 0 adverbios.

La gramática española es consecuente de la latina. Su objeto central de estudio es la oración gramatical, que en su estructura superficial (en términos generativistas) consta de un sujeto y un predicado; a su vez, el sujeto contiene un núcleo expresado en un sustantivo o su equivalente y uno o más modificadores representados por artículos y adjetivos. El predicado requiere de un verbo conjugado que se comporta como núcleo y de uno o más complementos. Lo característico del latín, del griego y del español es que cada una de estas

13 Los gramáticos históricos hicieron caso omiso del valor semántico de los lexemas y sintagmas, porque no existían los estudios semánticos y porque el significado es abstracto y voluble. Se entendía que la palabra nace con un determinado significado y este debe perdurar o morir con su forma. Uno de los méritos del cultismo es conservarlo para la eficacia de la comunicación. En efecto, esta razón sigue siendo válida al mirar retrospectivamente la lexicología española, porque las palabras que hoy empleamos, en su mayoría conservan la raíz semántica de la lengua que les dio vida. Somos los hablantes quienes hacemos asociaciones por asimilación, disimilación o contraste bien entre lexemas, bien entre estos y las realidades nombradas por sus cualidades, eventos y relaciones en los que participan, o valores. 
categorías sintácticas puede estar en el comienzo, en el medio o en el final de la oración y el significado no cambia, pero sí el sentido. A esta propiedad gramatical se le llama hipérbaton y que Villegas $\left(1960\right.$, p. 83) lo define en la "Regla $3^{\text {a }}$ - En latín se puede variar mucho el orden de la colocación de las palabras. Así: $<<$ el agricultor dio agua a las palomas $>>$ se puede decir:

Agricola dedit aquam columbis, o

Columbis aquam dedit agrícola, o

Aquam columbis agrícola dedit, etc."

Del mismo modo, en español el sujeto "el agricultor" puede ubicarse al comienzo de la oración, en el medio o al final. En total puede darse hasta veinticuatro órdenes a la misma oración y todos en voz activa, afirmativa. Esto no ocurre en inglés que solo posee un orden. ¿Por qué la flexibilidad? Hay varias repuestas que se pueden resumir en una: cada orden tiene una intención distinta. El hablante ubica en primer lugar el tema que le interesa. Así, en la primera le interesa decir algo del agricultor; en la segunda, de las palomas; en la tercera, del agua; en la cuarta, de la acción de dar, etc. La necesidad de este hipérbaton se debe a la pobreza comunicativa del idioma (latín o español) que necesita recurrir al orden sintáctico para precisar la semántica de la oración en una comunicación real y efectiva.

No obstante esta flexibilidad, en español no es común que el verbo esté al final cuando hay tres o más constituyentes como en *el perro al niño mordió ${ }^{14}$. Algunos órdenes pueden causar ambigüedad como en: *Se vende zapatos para niños de caucho; *se alquila vestidos para novias de segunda mano; *la comida pateó el caballo. "Exigimos que liberen a los secuestrados inmediatamente" (Claudia Gurisati, periodista RCN. 2305-2016. Noticiero de televisión del medio día). 0 en el mismo noticiero del día 27 de julio de 2016: "Necesario proteger los ojos del sol".

\section{Cambios fonéticos del latín al español}

En la historia de las lenguas, se han establecido "Criterios de clasificación lingüística" (Arciniegas, 1998, p. 157 y ss). Según este autor, hay cuatro criterios de clasificación: geográfico, etnográfico, morfológico y genealógico. El geográfico "Divide y clasifica las lenguas [...] según países y regiones [...] No es un criterio muy científico" (p. 157). "El criterio etnográfico distribuye los idiomas de acuerdo con las razas que pueblan el orbe" (p. 157). "El criterio genealógico compara la vida de las lenguas con la vida de los hombres"

14 El asterisco indica que la oración es agramatical. 
(p. 140). "El criterio morfológico tiene en cuenta únicamente la estructura de las lenguas" (p. 139).

En el estudio propiamente lingüístico del latín y del español, los historicistas se ocuparon de algunos aspectos del criterio morfológico, pero también fonético. Estos idiomas los asumen como "lenguas flexivas u orgánicas", por oposición a las "monosilábicas 0 aisladoras", además de analíticas y tonales (chino, birmano, siamés, anamita y otras lenguas de indochina $)^{15}$. Los lexemas de las lenguas flexivas constan de los morfemas raíz y desinencia variable; esta última permite identificar las funciones y relaciones sintácticas intraoracionales.

Saber cómo ocurrieron los cambios fonéticos, léxicos, semánticos y morfológicos en el paso del latín al español que hoy tenemos, así como los distintos tiempos en que ocurrieron e incluso las comunidades que los generaron, requirió de amplias, profundas y a veces desalentadoras investigaciones ante la falta de recursos fonográficos, de testigos de cada evolución. Fue una tarea ardua en manos de los historiadores de la gramática de la lengua, por lo que remito al lector a la bibliografía ${ }^{16}$ si su interés es el de conocer los intríngulis de la formación y evolución de la lengua, primero castellana y luego española.

Empecemos por las vocales. El latín clásico contaba con diez vocales, cinco largas y cinco breves: $\bar{a} \mathrm{a}, \bar{e} \mathrm{e}, \overline{1} \breve{1}, \bar{o} \breve{o}, \bar{u} \mathrm{u}$, y con tres diptongos: ae (breve), oe (larga), au (larga), que respectivamente se leían como 'e', 'e', 'o'. La brevedad o el alargamiento afectaban el significado de la palabra; no es lo que ocurre comúnmente en español. Solo los hablantes del latín sabían distinguir una vocal breve de una larga, de la misma manera que un francés distingue una 'e' abierta de una cerrada o de una muda.

- La vocal 'a' tanto breve 'ă' (măter > madre) como larga 'â' (sāpone > jabón) al español dio ' $a$ '.

- La vocal breve 'ĕ' al igual que el diptongo 'ae' también breve en contacto con consonante se transformaron en 'ie', pero en contacto con otra vocal o con ' $\mathrm{q}$ ' dieron 'i'. (sěrvus $>$ siervo, pĕtra $>$ piedra, aequalis $>$ igual, Deus $>$ Dios, caelum $>$ cielo).

15 Desde el punto de vista morfológico las lenguas se clasifican así: AGLUTINANTES porque las palabras se pueden segmentar en morfemas estructuralmente fijos que no se alteran en su forma en la composición de las palabras. AISLANTES o ANALíITICAS porque constan de un morfema que carece de derivados. SINTÉTICAS porque cada palabra está constituida por varios morfemas.

16 De los autores referenciados, sinteticé lo relativo a la fonética de las vocales y consonantes que expongo en este escrito. Atrás se expuso algunos cambios, aquí me permito presentar las reglas de los cambios vocálicos representativos y que nos ayudan a tener una idea de por qué las formas de las palabras que hoy usamos. 
- Tanto la 'è' larga como la 'č' breve y el diptongo 'oe' evolucionaron en 'e'. (Pētrus $>$ Pedro, minus $>$ menos, poena $>$ pena).

- Por su parte, la 'ī' larga dio 'i' (d⿳亠丷es > día, cìvitas $>$ ciudad), mientras que la 'ŏ' breve cambió en 'ue'(ŏvum $>$ huevo, nŏvus $>$ nuevo).

- La vocal 'ō' larga, así como la 'ŭ,' breve y el diptongo 'au' evolucionaron en 'o'. (ōculus $>$ ojo, lŭpus $>$ lobo, taurus $>$ toro). Por su parte, la vocal ' 'ù' larga dio 'u'. (lūna > luna, cūbicūlum > cubículo).

Algunos lexemas latinos pasaron duplicados al español. Son dobletes de origen común que han tomado diferente camino en boca del pueblo y del académico. El culto 0 académico se atenía a la lengua escrita y el vulgar a las leyes fonéticas inconsistentes. En la forma culta prevalece el significado original, mientras que la expresión coloquial resulta semánticamente de condiciones emotivas. Así tenemos expresiones como:

$\begin{array}{llll}\text { LATÍN } & & \text { CULTISMO } & \text { VULGARISMO } \\ \text { Augurium } & > & \text { Augurio } & \text { Agüero } \\ \text { Causam } & > & \text { Causa } & \text { Cosa } \\ \text { Directum } & > & \text { Directo } & \text { Derecho } \\ \text { Integrum } & > & \text { Íntegro } & \text { Entero }\end{array}$

En síntesis, el lenguaje culto (sermo urbanus) se conservó para la escritura y los eventos formales, y el popular o vulgar (sermo rusticus) se dejó para las conversaciones.

\section{Pronunciaciones latinas y su incidencia en la fonética y escritura del español}

Solo se tienen hipótesis de cómo se pronunciaba el latín entre los romanos. Ciertamente en latín no había palabras agudas, solo graves y esdrújulas. Los historiadores de la lengua hablan de una pronunciación "restituida", es decir, la empleada por los hablantes nativos; otra, la "eclesiástica" o "italiana" que se aproxima más al latín vulgar. Verbi gratia, en el latín clásico, los diptongos se pronunciaban con las dos vocales. Aedes (casa, morada) se leía /a-e-d-e-s/, pero en el latín vulgar se pronunció 'edes'. Vitae (vida) en latín clásico se pronunciaba /v-i-t-a-e/ y en el vulgar, 'vite'. En la evolución del latín culto al vulgar y luego a lo que hoy es el español, además de las vocales algunas consonantes se alteraron ya en su pronunciación, ya en su escritura, otras como la $\mathrm{Z}(/ \theta /)$ y la $\mathrm{Y}(/ \mathrm{Y} /)$ proceden del griego. La mayoría de consonantes del latín pasaron al alfabeto español. 
La letra 'C' delante de /e/ y de /i/ en italiano la pronuncian como /ch/, tal como se dice que se pronunciaba en un texto latino. Pero en español se siguió la pronunciación restituida, y escribimos palabras como 'Cicerón' y no 'Chicherón'. Las letras CH, en latín se pronunciaban como / $k /$, sonido consonántico, velar, oclusivo y sordo y derivó en palabras con la misma fonética y cuya escritura corresponde a la letra $\mathrm{C} o$ a las letras QU. En español encontramos palabras derivadas de este idioma como charitas $>$ caridad, Bacchus $>$ Baco, pachyderma $>$ paquidermo, chimaera $>$ quimera, chirographus $>$ quirógrafo.

Las letras PH en latín se leían como /-f-/ y al español dieron palabras con F. Ejemplo, philosophia > filosofía, triumphalis $>$ triunfal, phalangis, physica, physiologia. Por su parte, La letra $\mathrm{F}$ inicial de palabra en latín, en algunos casos se convirtió al español primero en sonido aspirado y luego en letra muda que en nuestro idioma se escribe como H. Ejemplo, filius/-a > hijo/-a, ficatus > hígado, farina, ferrum, facere, ficus. Este hecho nos ayuda a entender por qué existe la letra $H$ en español. Pero como nuestro idioma tiene herencia griega, esta letra también tiene sus raíces en la lengua helena.

En griego, además de los acentos agudo (' $)$, grave ( ' ) y circunflejo ( ) existen el espíritu suave (' ) y el espíritu áspero ( ' ) que se le marca a la vocal con que empieza una palabra. El áspero, que en griego se pronuncia con aspiración, en nuestra escritura se representa con la letra $\mathrm{H}$ que en los comienzos del español seguramente tenía sus rasgos de aspiración. Ejemplo, en griego 'agua' se dice v̋ $\delta \omega \rho$, de donde 'hidrógeno', 'hídrico', etc. Esta aspiración hoy se mantiene en palabras como 'halar', coloquialmente jalar, 'hartera' $>$ jartera, 'hierro' > jierro (del griego) y fierro (del latín), 'hediondo' > jediondo. Esta última, aunque no está reconocida por la RAE, es semánticamente diferente de la culta y solo se aplica a personas: *Fulano es jediondo con las mujeres.

La letra LL, en latín y en italiano se pronuncia como doble ele, pero en español es un sonido lateral, palatal, sonoro y que fonéticamente se representa como $/ K /$. Bastantes años hace que esta consonante dejó de pronunciarse como lateral y por asimilación con el sonido de la letra $Y$ se pronuncia como palatal /Y/. Como bien sabemos, los hispanohablantes pronuncian de igual manera 'pollo' (ave de corral) y 'poyo' (construcción rígida de la albañilería para soportar pesos) y para los escolares, por consiguiente, son palabras homógrafas. No es extraño encontrar en un escrito escolar:

\section{* “Ayá sobre el poyo el aya haya el poyo que haya para la cena”.}

La combinación de las letras GN y NN del latín culto originó, por su pronunciación, en español algunas palabras coloquiales con la letra Ñ que fonéticamente corresponde a una consonante sonora, palatal, nasal, y derivó otras cultas. Ejemplo, cognatus $>$ cuñado, 
acuñar y cognado, annus $>$ año y anuario, anual, pugnum > puño y pugna, pugnacidad, impugnar. Signum > señal, señuelo y signo, asignatura, insigne.

T+I+ VOCAL en latín se pronuncian /si/ y en español corresponde a la grafía Ci. Así tenemos: otium > ocio, traditionis $>$ tradición, negotium, palpitatio, oratio.

\section{Conclusiones}

Aquí retomamos unas investigaciones concluidas hace ciento cincuenta años, pero no superadas. No pretendimos repetir fragmentos de la historia del español por su historia, sino por los réditos de su conocimiento a la hora de asumir críticamente la comunicación lingüística en cada clase social, en cada región y en cada cultura.

Esperamos haber entendido: 1. que el origen y la gramática del español no son exclusivamente latinos. 2. Por qué nos llaman latinoamericanos o hispanohablantes. 3. Por qué darle importancia a las estructuras fonética, gráfica y morfológica, tanto en el aprendizaje y uso de la lengua como en el análisis discursivo. 4. Que el análisis de la forma no se puede separar del contenido, como dice Martiné (1974) que "todo hecho de experiencia que se vaya a transmitir, toda necesidad que se desee hacer conocer a otra persona, se analiza en una sucesión de unidades, dotadas, cada una de una forma vocal y de un sentido" (p. 20). 5. Que todas las lenguas evolucionan por la forma y por el contenido, según las condiciones sociales, culturales o de otra índole que en cada momento de la vida lingüística afecten a una lengua, y que nos permite entender la existencia de los dialectos.

\section{Referencias bibliográficas}

Alatorre, A. (1979). Los 1001 años de la lengua española. México, D.F.: Fondo de Cultura Económica.

Arciniegas, R. (1998). Del pensamiento a la acción por la palabra. Santa Fé de Bogotá, D.C., Colombia: Ediciones jurídicas Gustavo Ibáñez.

Camacho, H., Camporán, J., \& Castillo, F. (1998). Manual de etimologías grecolatinas. México D.F.: Limusa.

Gurisati C. periodista RCN. (23- 05-2016). Noticiero de televisión del medio día.

Lapesa, R. (1966). Historia de la lengua española. Madrid: Gredos.

Martiné, A. (1974). Elementos de lingüística general. Madrid: Gredos. 
Menéndez Pidal, R. (1985). Manual de gramática histórica española. Madrid: Espasa-Calpe.

Penny, R. (1991). Gramática bistórica del español. Barcelona, España: Ariel S.A.

Villegas, J. (1960). Dos años de latín; analogía, sintaxis y ejercicios (8a ed.). Bogotá, D.C.: Voluntad. 